\title{
We need to overpopulate bats not birds for prevention of Covid-19 totally
}

\section{Cemil Koyunoğlu}

Energy Systems Engineering Department, Engineering Faculty, Central Campus, Yalova University, Yalova, Turkey.

Corresponding Author: Cemil Koyunoğlu, Energy Systems Engineering Department, Engineering Faculty, Yalova, Turkey.

Received date: November 24, 2020; Accepted date: November 27, 2020; Published date: December 26,2020

Citation: Cemil Koyunoğlu, (2020) We need to overpopulate bats not birds for prevention of Covid 19 totally; J Clinical Medical Reviews and Reports. 2(9); DOI:10.31579/2690-8794/054

Copyright: (C) 2020, Cemil Koyunoğlu, This is an open access article distributed under the Creative Common Attribution License, which permits unrestricted use, distribution, and reproduction in any medium, provided the original work is properly cited.

\begin{abstract}
Mink's role in nature is important. Since mink is a carnivorous species, there are small mammals such as crayfish, snakes, turtles, small birds, mice, rabbits, insects, and crustaceans in the food chain. The most important of the practices that threaten the life of the mink is the cutting of the trees where the mink lives for furniture or energy production. Another threat is that their fur is made into clothes, as in Denmark, where 1 billion dollars of exports are made annually. However, the recent acceptance of the covid virus as a host to humans resulted in 17 million minks being buried in the mass grave in just the first week, and then the entire culling of them. Here it is not the resignation of a responsible prime minister. It is the threat that the mink, which forms part of the food chain, will suddenly increase the population of small birds, which play a key role in world food production. Of course, the purpose here is not to blame everyone unconsciously. However, instead of interfering with the chain in nature, the mink should be kept under quarantine by considering the antibody formed in the bodies of the mink as a treatment tool. Now the world should be prepared for unexpected adverse effects, such as the growing bird population with the disappearance of those 17 million minks. The species that need to be increased in the fight against Covid-19 are bats, the main source of the virus. Because bats may have carried a combination of SARS and MERS viruses from the same source in the past as a defense mechanism to adapt to nature with the depletion of water flies in the world with the restriction of water resources. The presence of any population in nature that is more than normal may further limit the use of a biosource present in nature. Every intervention in nature inevitably confronts humanity. As an alternative thought, it may be suggested that minks should not be considered as a commercial purpose in human life or should be restricted.
\end{abstract}

Keywords: Covid 19; SARS; MERS viruses

\section{Introduction}

For example, a study conducted in the Netherlands showed that the viral RNA present in the mink covid-19 virus was detected as respirable powder. However, in mink, this virus causes pneumonia and lung inflammation as in humans. Mink can be considered as an important tool from drug therapy to be developed for humans [1]. Below, we can see the spread of coronavirus seen in minkes along with other living species (Figure 1).

Figure 1. ACE2 protein phylogenetic divergence and in vivo model severity. Left panel, fast minimum evolution distance tree for ACE2 protein sequences using Griphin for evolutionary distance, unsorted.
Species included are Gallus gallus (Chicken), Anas platyrhynchos (Duck), Cavia porcellus (Guinea Pig), Mustela putoris furo (Ferret), Canis lupus familiaris (Dog), Felis catus (Cat), Sus scrofa (Pig), Rousettus aegyptiacus (fruitbat), Mesocricetus auratus (Golden hamster), Mus musculus (Mouse), Callithrixjacchus (Common Marmoset), Macaca mulatta (Rhesus macaque), Macaca fascicularis (Cynomolgus Macaque), Chlorocebus aethiops (African Green Monkey) and Homo sapiens. Macaques are represented as one image due to close divergence. The severity of the disease is color-coded from refractory to infection (BLUE, no virus detected) to severe (RED, shedding). Common Marmoset and Guinea Pig have only been assessed for SARS-CoV, all others with SARS-CoV-2. The scale indicates $10 \%$ amino acid divergence [1]. 

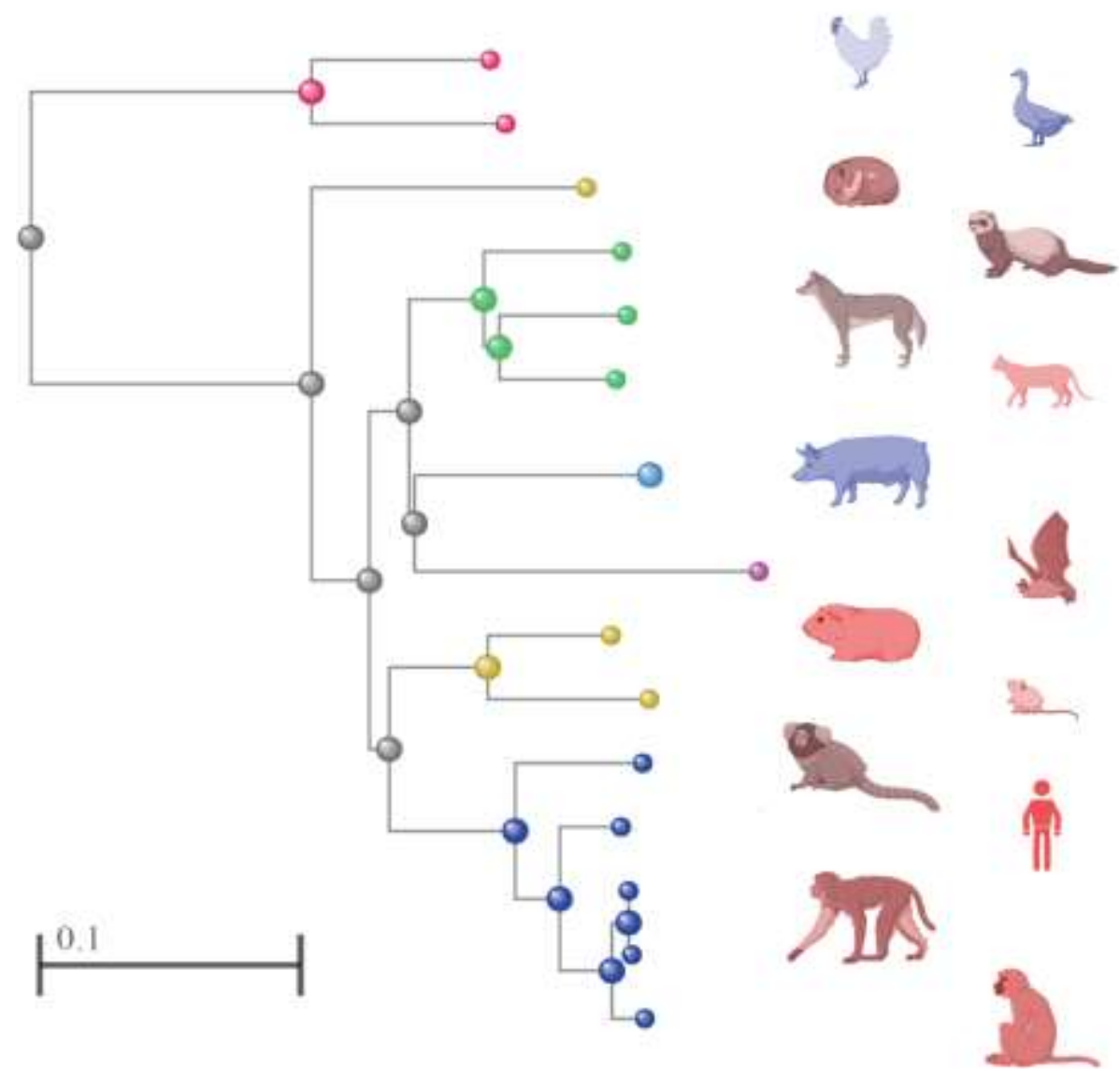

Instead of culling the minks, a scientific path like the following could be used (Figure 2).

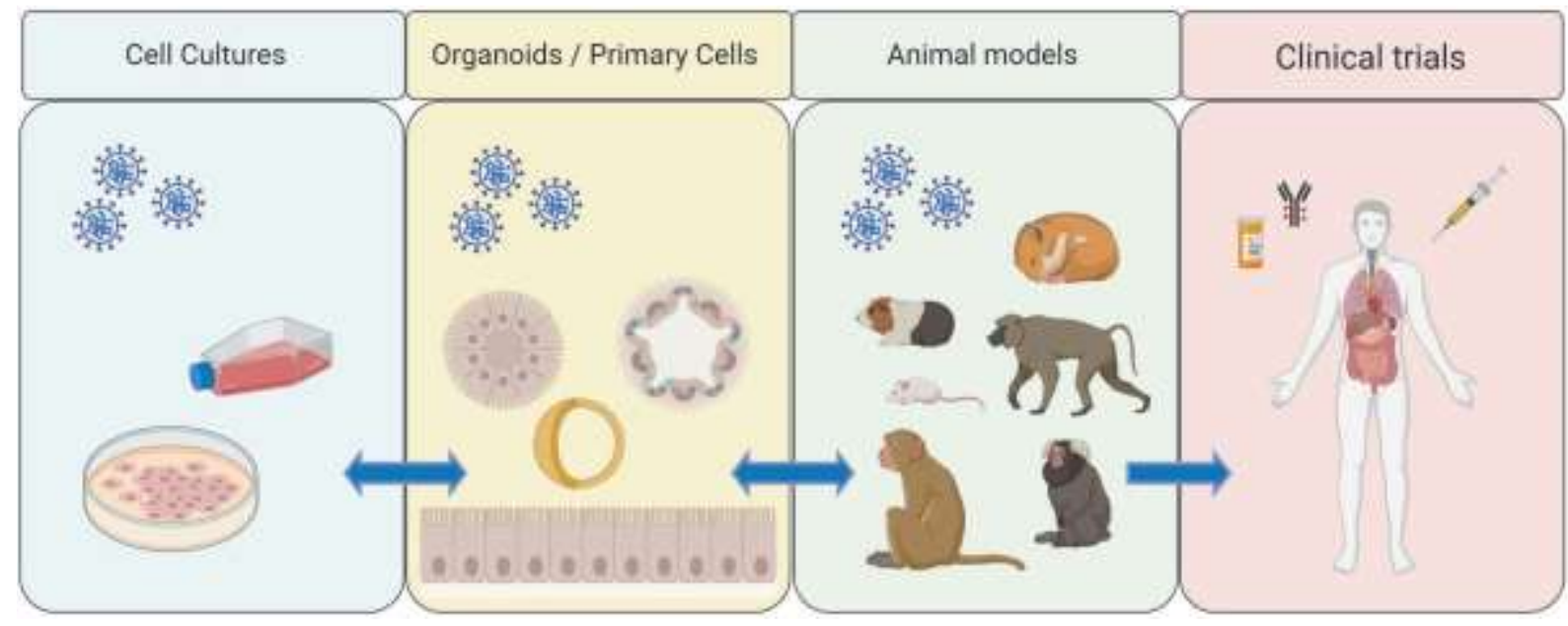

Figure 2. Overview of the different translational model systems used to interrogate disease mechanisms of SARS-CoV-2. Cell culture and organoid/primary cell infection studies are critical for deciphering the cellular mechanisms of SARAS-CoV-2 pathogenesis and for highthroughput identification of leading drug candidates. In vitro findings can then be directly translated to animal models such as mice, hamsters, guinea pigs, and non-human primates to assess the safety and efficacy of drugs and vaccines before progressing to human clinical trials [1].

Depending on the course of the disease between a living thing and a human, a comparison as follows is possible (Figure 3). 


\section{Human clinical features}

\section{hACE2 mouse models}

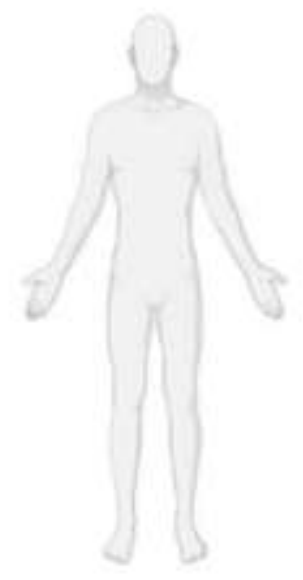

\section{High viral lung titres}

\section{Pro-inflammatory cytokine production}

\section{Lung damage and pulmonary decline}

\section{Clinical signs eg weight loss, pneumonia}

Figure 3. Comparison of disease features shared between humans with COVID-19 and mouse models of SARS-CoV-2. Both humans and mice display similar clinical signs such as weight loss and pneumonia. Severe infections are often associated with increased pro-inflammatory cytokine production, accompanied by high viral lung titres which correlate with extensive lung damage and significant pulmonary decline [1].

\section{Conclusion}

We have to take care of animals in our World (Figure 4).

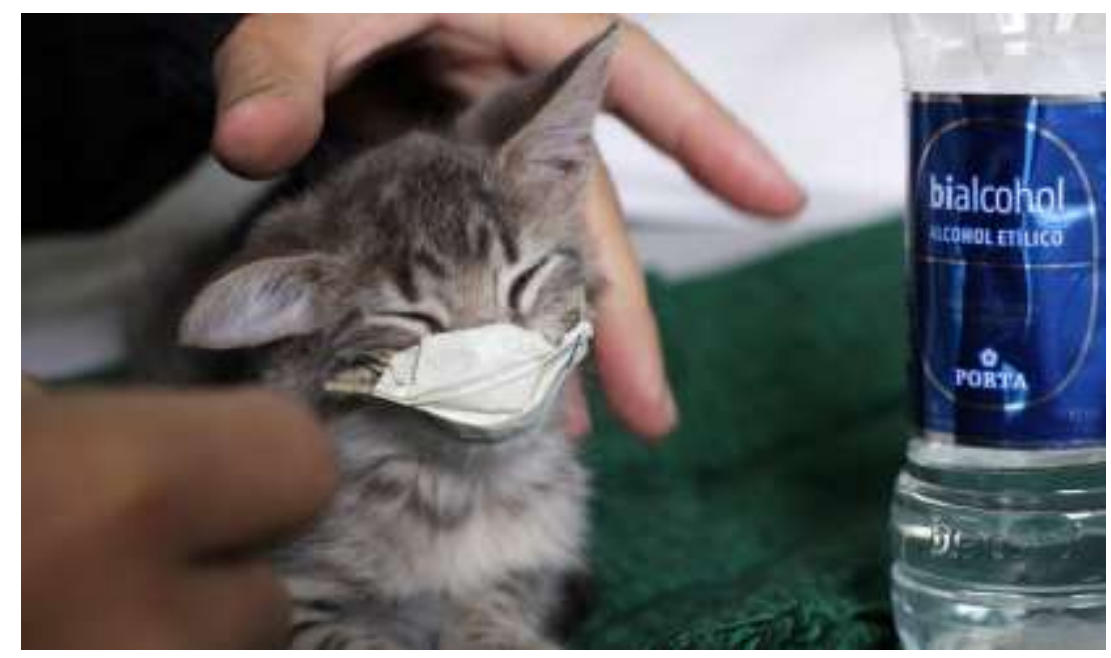

Figure 4. Cat also can be infected [2].

\section{References}

1. Johansen, M. D., Irving, A., Montagutelli, X., Tate, M. D., Rudloff, I., Nold, M. F., . . Hansbro, P. M. (2020). Animal and translational models of SARS-CoV-2 infection and COVID-19. Mucosal Immunology, 13(6), 877-891.

2. Mallapaty, S. (2020). What's the risk that animals will spread the coronavirus? 